\title{
PRELIMINARY RESULTS OF PRUNING NORWAY SPRUCE IN PLANTATIONS
}

\author{
By James D. Curtrs ${ }^{1}$
}

$\mathrm{T}^{\mathrm{H}}$

HE SIGNIFICANCE of the results from artificial forest pruning must not be overlooked, and this is especially true where the ultimate product is to be used as lumber. When pruning is carried out for the purpose of pole production, strengthening a central core with knotless wood, defects resulting from the operation are not so vital where rapid, defectless healing is essential. When lumber is sawn from pruned logs it is necessary that the growth of wood over branch scars be free from blemishes in order that a maximum quantity of high grade boards can be secured. Pitch, bark, air pockets, or discoloration in the direct vicinity of a healed branch cut will detract from the value of a board sawn from that region and all are highly undesirable types of defect. Discoloration, one of the most common defects in some species, often extends out over a large area, both radially and tangentially, in the stem. If this occurs several boards may be reduced in value by the action of stain which has spread from the branch wound. Unless the operator makes an effort to control defect when pruning his crop trees, the resulting lumber may yield less in value than if they were left untreated. Pruning in such cases, where the cost compounded over a number of years coupled with depreciation in lumber quality, represents a sizeable financial outlay, cannot be justified. Furthermore, presuming there is good growth after treatment, the most important outcome of a pruning operation is the time required for branch scars to heal free of defect. Closed wounds of branch cuts viewed externally often present an erroneous picture of what has actually taken place within the tree and several additional years may be required after the branch wound has apparently healed before subsequent diameter growth produces clear wood.

In no species, has the question of defect and growth diminution provoked more dissension than that of Norway spruce, (Picea Abies Karst.). The pros and cons of the practicability of pruning this species have been set forth for nearly a century. This has been especially true in Germany, where early. in the 19th century, intensive forestry practices were begun in an effort to recuperate from the drain on her forest resources during the Middle Ages. Although the greatest effort was for a time centered on quantity production, foresters soon appreciated the importance of quality and methods were adopted to produce high grade lumber in a minimum of time. Pruning was accepted 
as the main solution. Although English investigators also devoted considerable time to Norway spruce at about this time, German foresters carried out extensive experiments and treated the subject more exhaustively in their country where Norway spruce was being planted and regenerated naturally over large areas. It is pertinent, however, to review literature from both countries to better exemplify the diversity of results and opinions which have prevailed from time to time.

Hutchison (1868) records that spruce, "fore-shortened," or "disbudded" (the removal of terminal buds and branchlets from branches whose growth it is desired to check) produced one-third more growth in diameter than untreated trees growing in the immediate vicinity. On the other hand, Mattl (1927) found that conservatively pruned Norway spruce took twice as long to make the same diameter growth as untreated ones and that height growth also fell off following pruning.

The artificial pruning of Norway spruce has been condemned chiefly on account of two factors, the time required to heal and the defect resulting from the operation. In this connection, however, it is possible that conclusions were based on pruning policy and technique which could have been improved. For instance, according to May (1888) Kienitz contended that the pruning of green limbs should be confined to "small" limbs, i.e., not over $23 / 4$ " in diameter and preferably employed on branches very much smaller. Kienitz, who proved statistically that lumber from pruned spruce was a very much more valuable product than that from unpruned trees, recommends the start of pruning at 35 years and that only dead branches be taken. May (1888) explains further that Alers, one of the leading exponents of pruning when it enjoyed its most extensive use, also suggests the first pruning at 30 years of age and that only dead branches be removed. Again, May (1888) points out that Uhlig goes so far as to suggest pruning at the time of the first thinning which for spruce in Saxony would be 55 to 65 years. Guth (1905) found that the green pruning of spruce caused pitch pockets of a "5 Mark" size and larger and even removed the possibility of using the wood for lumber. Lakari (1921) discovered, after a careful investigation, that green pruning resulted in rot and discoloration of the pruned stem. It is the writer's opinion, that, with the delay of pruning for as many as 40 years on an average, the branches may have reached a size far beyond that which it was practicable to remove. If the branches were dead, occlusion of the cut was inevitably slow and during that time rot had free access to the tree. On the other hand, if large branches were green when pruned, resin flow from the cut surfaces may have been considerable, which could have produced 
much discoloration in the surrounding wood, especially if diameter growth was slow. This condition would be aggravated if the branches were not carefully and correctly pruned, leaving a rough or uneven surface. Mayer Wegelin (1932) confirms this opinion, stating that much of the disfavor in regard to pruning of spruce has come about by leaving the operation until too late. In an investigation of old pruning plots, he demonstrated that pruning either dead or live branches in a stand around 40 years of age produces anything but a desirable result. It can be appreciated, therefore, that investigators dealing with Norway spruce, at a time when pruning was first being considered, worked with branch sizes too large for satisfactory healing.

The purpose of the present study was to determine the effects of pruning the green branches from Norway spruce including the rate of healing, the extent and nature of defect, and the disturbance in growth rate.

Since opinion has differed so widely on the merits of pruning Norway spruce artificially, an intensive study to serve as some indication of what might be expected from the treatment, seemed in order. It is questionable if pruning of Norway spruce in plantations can be justified at the present time to improve lumber quality, but information on such a species which has many commercial possibilities and which has already been extensively planted throughout many parts of the country, should prove of value in future management.

Material used was collected ${ }^{1}$ from the Rainbow Forest Plantations ${ }^{2}$ and Black Brook Plantations. ${ }^{3}$ The trees selected for study on the Rainbow Plantations were on a tract of 2.6 acres planted in the spring of 1906 with two year seedlings of northern white pine (Pinus strobus L.) and Norway spruce spaced $6 \times 6$ feet, the two species alternating by rows. Hicock (1924).

In April, 1934, three straight trees were chosen for analysis, two dom. inants and a co-dominant. (See Table A).

TABLE A

Measurements of the Three Sample Trees

1934

$\begin{array}{lccc}\text { Crown Class } & \begin{array}{c}\text { Diameter } \\ \text { (Inches) }\end{array} & \begin{array}{c}\text { Height } \\ \text { (feet) }\end{array} & \begin{array}{c}\text { Age } \\ \text { (years) }\end{array} \\ \text { Dominant } & 6.00 & 36.5 & 30 \\ \text { Dominant } & 5.15 & 33.0 & 30 \\ \text { Codominant } & 4.50 & 30.5 & 30\end{array}$

1 The author wishes to acknowledge assistance of Dr. H. J. MacAloney in the collection of material from Rainbow Plantations.

2 Property of Connecticut Agricultural Experiment Station; material through courtesy and co-operation of Mr. Henry W. Hicock, Assistant Forester, Connecticut Experiment Station. 3 Property of Harvard Forest located at Hamilton, Mass. 
The trees were felled and cross-sectioned at each node for the pruned portion of the bole. Several sections were made at each node in order that all branches would be included and to afford a better opportunity of examining the exposed cuts. Branches were chosen so that the pith of the branch was exposed to view at the point where it was pruned. In this way all measurements of branch diameters were as though they had been measured across the face of the cuts.

The condition of each branch at the time of pruning was determined by the arrangement of the annual rings of the main stem contiguous to the pruned branch, as shown by the cross sections. Where branches were green when pruned, the last few annual rings before pruning tended to turn outward and along the branch and parallel to it. The last annual rings of a dead branch (depending on how long it had been dead) were reversed in arrangement and were directed inwards along the branch towards the center of the tree.

In the examination of the cuts three degrees of occlusion were recog. nized. Cuts completely healed free of defect where clear wood was being produced; these were designated as "F D" cuts. Cuts which had healed as viewed externally but were not yet producing clear wood were designated as " $H$ " cuts. Finally, those which' were still open and had not yet completed occlusion over the cut surface were designated as " $O$ " cuts.

It soon became obvious that, in some cases, slight stubs had been left by not pruning close enough to the stem. Although the length of these stubs seldom exceed $3 / 8$ of an inch as measured from the tree stem inside bark, it was apparent that cuts should also be classified under two headings, namely, those which had been cut flush with the trunk, "Even cuts," and those where the bark collar had prevented a close cut and a stub had been left, "Uneven cuts." Forty-six of the former were represented in the material examined and 19 of the latter.

TABLE B

Types of Occlusion for Even and Uneven Cuts

\begin{tabular}{lcc}
$\begin{array}{c}\text { Type of } \\
\text { Occlusion }\end{array}$ & \multicolumn{2}{c}{$\begin{array}{c}\text { Number of Cuts } \\
\text { Represented }\end{array}$} \\
Fven & Uneven \\
F D & 39 & 7 \\
H & 2 & 2 \\
O & 5 & 10 \\
(Basis-cuts) & 46 & 19
\end{tabular}


In Table $B$ is shown the total number of both kinds of cuts and their types of occlusion for the five years of growth following pruning. It will be seen that the highest number of "F D" cuts, those healed and producing clear wood, occur under the heading of "Even cuts" and conversely, the highest number of " $\mathrm{O}$ ", or open cuts, are to be found in the "Uneven cut" column.

Two cuts healed, but not yet producing clear wood, occur in each classification. The old and well established but often ignored rule of cutting close to the bole to insure rapid healing is revealed by these figures. The average time for the "Even cuts" to heal free of defect was 3.4 years contrasted with 3.5 years for the "Uneven cuts," a small but significant difference in favor of the "Even cuts." Table C shows the size of the branch cuts by quarter inch classes and the type of occlusion for all cuts in each class.

\section{TABLE C}

Size of Cuts, Type of Healing, and Average Number of Years to Heal Free of Defect

\begin{tabular}{|c|c|c|c|c|c|}
\hline \multirow{2}{*}{$\begin{array}{c}\text { Size of } \\
\text { Cut }\end{array}$} & \multirow[b]{2}{*}{ Total } & \multicolumn{3}{|c|}{ Occlusion } & \multirow{2}{*}{$\begin{array}{c}\text { Number of } \\
\text { Years to }\end{array}$} \\
\hline & & F D & $\mathrm{H}$ & $\mathrm{O}$ & \\
\hline Inches & Cuts & $\%$ & of & Cuts & Heal F D \\
\hline $0-.24$ & 1 & 100 & - & - & 4.0 \\
\hline $.25-.49$ & 41 & 75 & 5 & 20 & 3.5 \\
\hline $.50-.74$ & 20 & 75 & 5 & 20 & 3.5 \\
\hline $.75-1.00$ & 3 & - & 33 & 67 & - \\
\hline
\end{tabular}

The extreme right hand column gives the average number of years to heal free of defect. It would seem that, other things being equal, branches under one inch in diameter heal at approximately the same rate. Of 11 cuts, the branches of which were dead when pruned, two were open, one was healed, and eight required an average of 3.5 years to heal free of defect. If the branches are properly pruned then, small, dead branches heal at the same rate as slightly larger, green branches.

No diameter measurements were made when the trees were pruned but as far as could be ascertained, the largest tree, measuring $6.0^{\prime \prime}$ d.b.h. in 1934 was close to $4.1^{\prime \prime}$ in 1929 . It is interesting to observe that 100 per cent. of the cuts on this tree, which was in the dominant crown class, were healed free of defect. In contrast, the slower growing dominant and codominant had only 55 and 60 per cent. of their cuts sufficiently healed as to produce clear wood. 
In the 65 cuts examined, 14 or 21 per cent. had defects of either ingrown bark or pitch pockets, but no cases of air pockets or discoloration were found. It is highly significant, however, that no defect extended radially from the cut face more than $.30^{\prime \prime}$. In Table $\mathrm{D}$ is presented the nature, occurrence, and extent ${ }^{1}$ of defect. ${ }^{2}$

\section{TABLE D}

Extent, Nature, and Occurrence of Defect in 65 Branch Cuts

Extent of Defect
(Inches)
.10
.15
.20
.30

$\begin{array}{cc}\text { Kind } & \begin{array}{c}\text { Number of } \\ \text { Occurrences }\end{array} \\ \text { Bark - Pitch } & 4 \\ \text { " } & 5 \\ \text { Bark } & 4 \\ \text { " } & 1\end{array}$

In the Black Brook Plantations, ${ }^{3} 20$ dominant trees with crowns entirely green were pruned to a height of eight feet from the ground, or, as high as a man could conveniently reach with a saw. ${ }^{*}$ This meant that the length of green crown removed in pruning, as measured in relation to total height of tree, ranged from 40 to 64 per cent. and an even higher percentage in leaf surface is considered. The plantation was located on an isolated knoll where the soil was gravelly with a thin humus layer. Planted in 1921 with $2-2$ stock and a $3^{\prime} \times 3^{\prime}$ spacing, it received one weeding in 1932 which removed the red maple and oak sprouts and gray birch. The diameters of the pruned stems averaged 2.2 inches at breast height and ranged from 1.3 inches to 2.9 inches. Heights of pruned trees averaged 15.3 feet and ranged from 12.5 to 19.9 feet. The stand had reached a stage where crown classes had expressed themselves so that dominants were easily recognizable. On the whole, the prospects of pruning up eight feet from the ground appeared feasible from the severity standpoint and an advantage in so far as the first operation to obtain clear length was concerned, since the stems were of such a size that the next pruning could be final.

Borings were taken in 1936 at $41 / 2$ feet above the ground to determine the influence of the pruning on diameter growth and each year's growth

I This was measured from the cut face and in a radial direction.

2 Defects less than .10" in length were not recorded.

3 Tangential spread of defect may be considered as inconsequential inasmuch as it would be confined to a single board whose width can be determined by the radial measurement of defect.

4 The author wishes to acknowledge the aid of B. C. Goodell and M. E. Raymond, students at the Harvard Forest, in the field measurements.

5 Henry Disston \& Sons hand pruning saw No. 7, 18" blade. 
for the past six years was recorded. Height growth for the last six years was also measured by using a 20 foot extension pole. In addition to present diameter breast high, the number of healed and unhealed cuts (as seen externally) were recorded for each tree. Blow in Table $E$ is shown the percentage of cuts, healed and open, on the 20 pruned stems after three years of growth for trees under 3.0" and for those over 3.0" in diameter.

\section{TABLE E}

Percentage of Healed and Open Cuts After

Three Years of Growth

$\begin{array}{lllll}\text { Under 3.0" d.b.h. } 1936 & 32 \% & 68 \% & 326 \\ \text { Over " ". " } & 49 \% & 51 \% & 404\end{array}$

With only two exceptions, trees less than $3.0^{\prime \prime}$ in d.b.h. in 1936, were less than $2.0^{\prime \prime}$ in diameter breast high in 1934 and those trees over $3.0^{\prime \prime}$ d.b.h. in 1936 were greater than 2.0" d.b.h. in 1934. The figures in Table $\mathrm{E}$ would seem to indicate again that growth rate has some bearing on healing, since those cuts on trees over 3.0" d.b.h. were represented by a greater majority (17 per cent.) over those cuts still open.

To determine the nature of healing, an unweeviled tree (over $3^{\prime \prime}$ in diameter in 1936) was cut and cross sectioned at each node. Three or four cross sections were made at each node to include all branches. The types of healing for the branch cuts as described earlier and used in the analysis of the material from the Rainbow Plantations are given in Table F. In spite of precaution taken to eliminate stubs of any kind when the trees were pruned, a few were found. Also, there were some cases where a "shoulder" existed at the base of branches in the upper part of the pruned length. It did not seem advisable to remove these when pruning owing to the large cut which would have been created. As before these latter cuts, however, have been designated "Uneven cuts" in Table F along with typical "Uneven cuts."

TABLE $\mathrm{F}$

Types of Healing for Even and Uneven Cuts

$\begin{array}{ccc}\text { Type of } & \text { Number of Cuts } & \text { Represented } \\ \text { Occlusion } & \text { Even } & \text { Uneven } \\ \text { F D } & 16 & 6 \\ \text { H } & 1 & 1 \\ \text { O } & 2 & 2 \\ \text { (Basis-cuts) } & 19 & 9\end{array}$


Although the number of branch cuts is not large, the same trend is shown that stubs of any kind will slow up the healing process. Also, the percentage of "Even cuts" which healed free of defect is much higher (18 per cent.) than those "Uneven cuts" which evidently require a longer time. Likewise, there is a lagging in the $\mathrm{H}$ and $\mathrm{O}$ types of occlusion, each type being represented by a higher percentage under the "Uneven" type of cut than under the "Even" type.

No defect of any kind was found in the 28 cuts examined.

In Table $G$ are set forth the sizes of cuts and the types of occlusions. It would seem that occlusion was not affected by size inasmuch as several small cuts were still unhealed. There is the possibility that an occasional lower branch was dead when pruned and also several small branches had stubs. On the other hand, larger cuts in the stem near the base of the crown which experiences increased diameter growth following pruning, healed free of defect.

TABLE G

Branch Sizes, Types of Occlusion, and Average Number of Years Necessary to Heal Free of Defect

\begin{tabular}{lccc} 
Size of & \multicolumn{2}{c}{ Occlusion } & Average Years to \\
Cut & Total & FD H O & Heal \\
Inches & Cuts & $\%$ of cuts & FD \\
$.25-.49$ & 16 & 75 13 12 & 2.6 \\
$.50-.74$ & 11 & $81-19$ & 2.7 \\
$75-1.00$ & 1 & $100--$ & 3.0
\end{tabular}

To determine, as far as possible, to what extent pruning affected the growth of pruned stems, an equal number of trees, dominant in the fall of 1934 when the others were pruned, were measured. Diameter at breast height and height growth were recorded for the three years prior to 1934 and the three years following. These results are set forth in Table $\mathrm{H}$.

TABLE $H$

Comparative Total d.b.h. and Height Growth of 20 Pruned and Unpruned Stems for Three Years Before and Three Years

After the Year of Pruning.

Unpruned Pruned

Percentage Percentage

Diameter growth-inches

Before After Decrease Before After Decrease

Height growth-feet

5.92

66.8

4.92

16.9

$10.60 \quad 7.40$

14.3

(Basis-trees)

20

20 
Determining the effect of the severity of pruning on height growth was made difficult by the fact that 16 of the 20 trees pruned had been weeviled since the year of pruning and 18 of the 20 unpruned trees. To what extent this weeviling affected diameter growth it is difficult to say, but in all cases except one (where it was equal) the periodic radial growth at breast height decreased during the three years after pruning from the preceding three years. In the pruned trees, there were only five instances where the current year's growth equalled or exceeded the last year's growth prior to pruning. Smallest radial growth was experienced by a tree weeviled two years in succession. Indications of radial growth as afforded at breast height indicated that not a few trees had recovered and were making diameter growth equal to that before pruning:

It will be seen from Table $\mathrm{H}$ that the percentage of decrease in diameter growth experienced by both groups of trees is approximately equal. It is felt, therefore, that severe as the pruning was, this decrease cannot be attributed directly to pruning but possibly to such factors as the start of serious root competition, soil conditions, climatic influences, weeviling, or the increase of diameter growth in the upper part of the bole (near the base of the crown) at the expense of decreased growth at d.b.h.

\section{CONCLUSION}

From the above trends, it would seem that Norway spruce can be advantageously pruned for the first time before a plantation is more than 20 years old on most sites. Dominants and co-dominants are between 20 and 25 feet tall according to Hosley (1936), most of the branches are alive and of a size (about one-half inch in diameter) conducive to healing more rapidly than those of white pine, which on medium sites require at least 10 years to heal free of defect, Hawley and Clapp (1935). No defects of consequence may be expected to follow the pruning if it is done correctly and carefully. Inasmuch as Norway spruce is often weeviled, it is believed that pruning, in the majority of cases, should be delayed until dominants reach a height of approximately 25 feet. If this is not done, some pruned trees may lose their dominant position in the stand as well as become deformed at some point in the pruned length. Inasmuch as the trees examined in this study were growing on sites 30 and 50, Hosley (1936), there is reason to believe that cuts on pruned Norway spruce on sites 60 and better would heal even more efficiently than those just described. Since any profit which may accrue as a result of artificial pruning must be calculated not from the time of the operation, but from the time clear wood is pro. 
duced, it can be appreciated that Norway spruce appears from this study to have distinct advantages over white and red pine.

The investigations described in this paper are being continued to learn the results of high pruning ( 8 to 18 feet) of Norway spruce in plantations, and time and costs of the entire operation.

\section{LITERATURE CITED}

Fankhauser, F. Uber den Einfluss der Aufastung auf die Stammform. il. 1912 Schweizerische Zeitung fur Forstwesen. V. 63: 329-34.

Guth, Zue Erziehung der Fichtenbestände. 1905 Zeitschr. F. u. Jagdw. 37(9):592-94.

Hawley, R. C. and Clay, R. T. 1935

Hicock, Henry W 1924

Artificial Pruning in Coniferous Plantations. Yale University, School of Forestry, Bul. 39.

Hosley, N. W. 1936

The Rainbow Forest Plantations. Connecticut Agricultural Experiment Station. Forestry Publication No. 15.

Hutchison, Robert 1868

Kunze, M. 1921

Norway Spruce in the Northeastern United States. Harvard Forest Bulletin 19. Harvard Forest Bulletin 19. Harvard Forest, Petersham, Massachusetts.

On the Pruning of the Rarer Conifers. Transactions of the Royal Scottish Arboricultural Society. V. 4:170-6.

Untersuchungen über den Einfluss der Beastung auf die Schaftform der Fichte. Mitt. Sächs. Forst. Versuchsanstalt II (3), Tharandt.

Lakari, O. J. 1921

Communications ex instituto quaestionum forestalium Finlandiae editae 2. Helsinki, 1920. Centralblat fur das gesamte Forst. 47:101-104.

Mattl, K. 1927

Einfluss der Schneitelung der Fichte auf Bodengüte und Zuwachs. Centralbl. f.d.g. Forstw. 53(3-4): 92-106.

May, K. J. 1888

Die Entwickelung der Aufastungstechnick und Aufastungslehre seit 1860; ein beitrag zur geschichte des deutschen Waldbaues. Inaugural dissertation, 55 pp., Munchen.

Wegelin, H. Mayer 1932

Ästigeit und Ästung Forstarchiv. Aug. 1, 1932. Vol. 8, No. 15:261-6. 


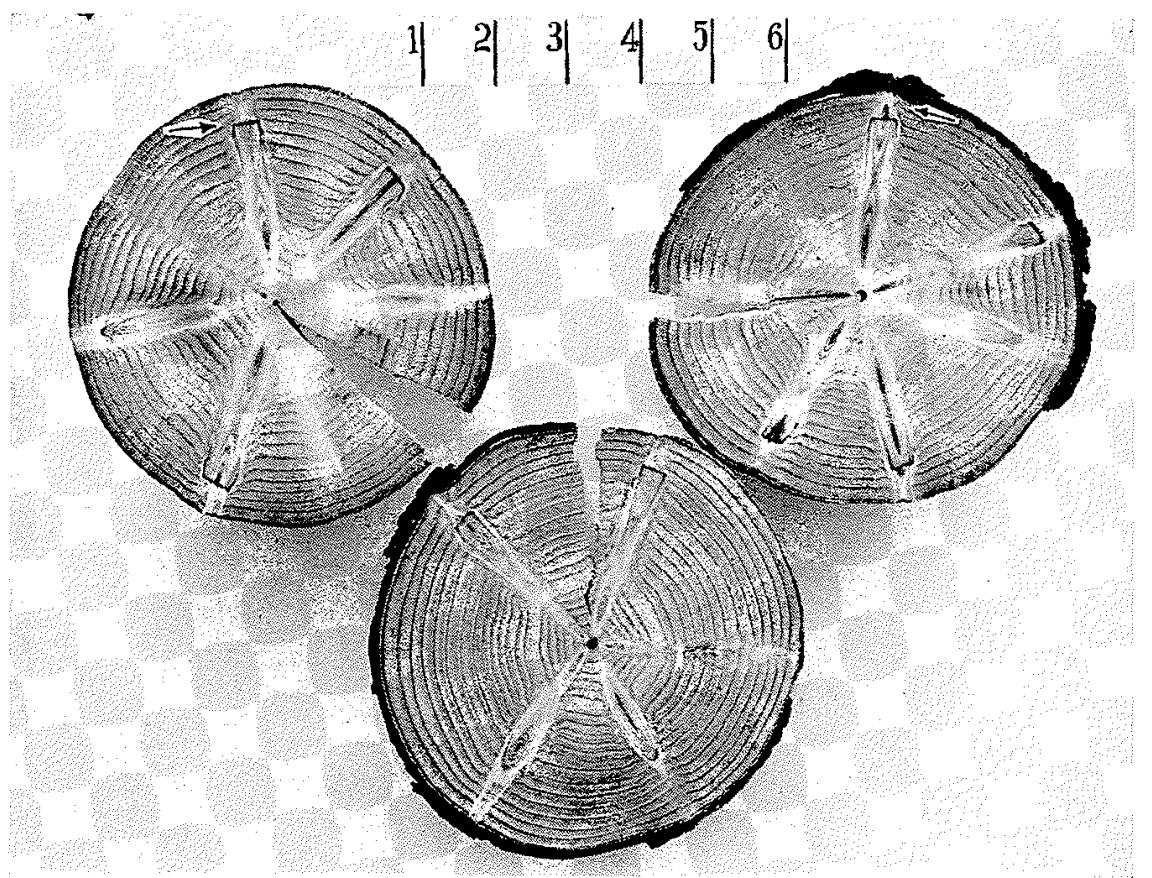

Figure I. Sections from the sample trees taken at the Rainbow Plantations five years after pruning. The arrow on the upper right section shows a $.20^{\prime \prime}$ bark pocket defect. The arrow at the left shows a branch cut producing clear wood after three years of growth. 


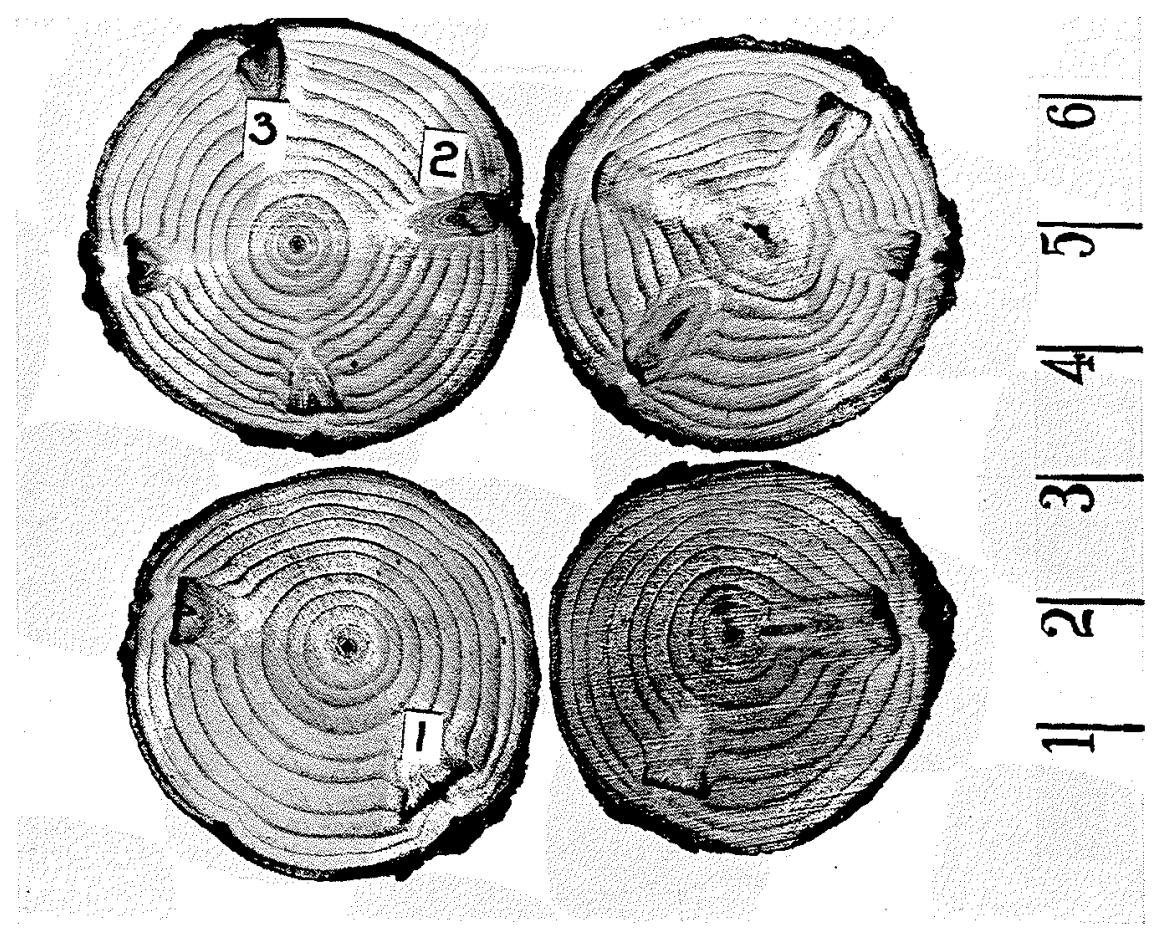

Figure II. Sections from the sample tree taken at the Black Brook Plantations, three years after pruning.

1. A .65" branch cut face, properly pruned and healed free of defect in a little more than two years.

2. A $.30^{\prime \prime}$ dead branch cut, improperly made, still open after three years of growth.

3. A. $35^{\prime \prime}$ live branch, unevenly pruned, (stub left at right) still open after three years of growth. Notice how callus has grown over to center of cut from left side, where the cut was made close leaving no stub. 


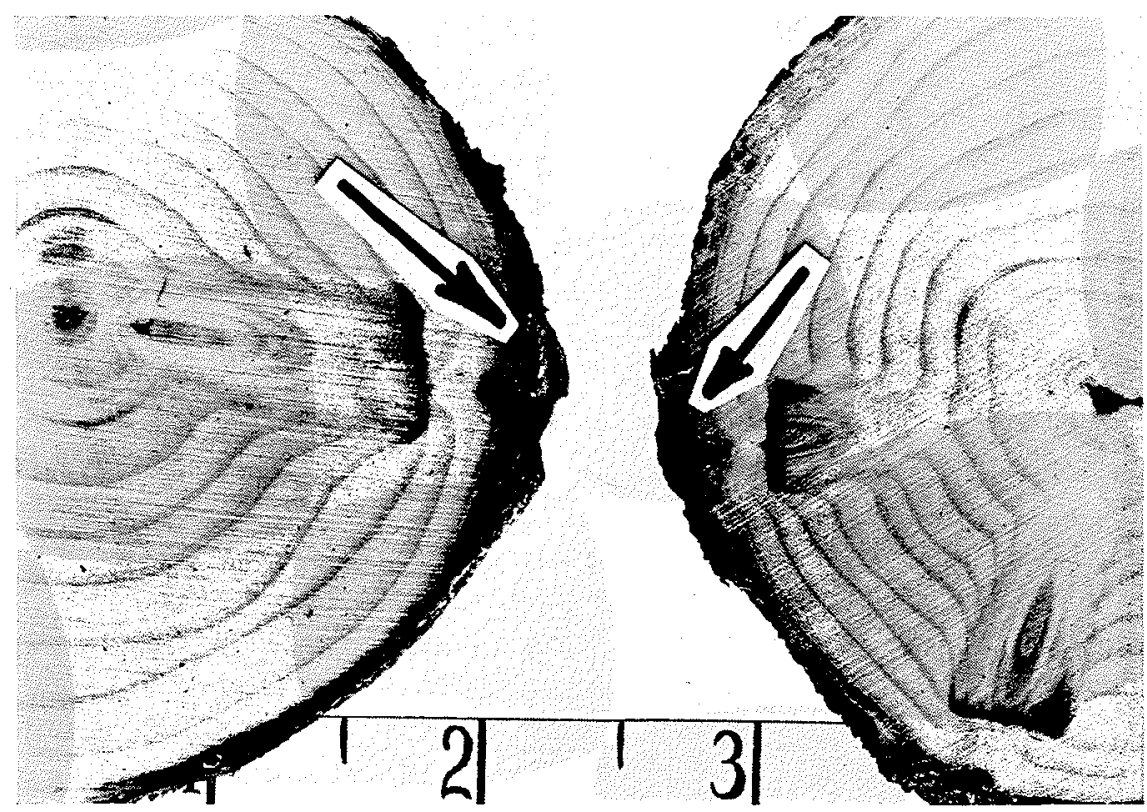

Figure III. Two branch cuts from sections of a pruned stem in the Black Brook Plantations. Arrows point to two incrustations of pitch. The pitch was exuded from the branch stubs and squeezed out by the callus as it rolled over the cut. This formation of clear wood two years after pruning can only be expected if small, thrifty trees are properly pruned. 